\title{
Evaluating Rehabilitation Exercise Performance Using a Single Inertial Measurement Unit
}

\author{
Oonagh Giggins, Daniel Kelly and Brian Caulfield \\ Clarity Centre for Sensor Web Technologies \\ University College Dublin \\ Dublin, Ireland.
}

\begin{abstract}
Inertial measurement units (IMUs) may be used during exercise to provide feedback on exercise technique. However the number of IMUs that are required to deliver effective feedback during lower limb exercises has not yet been established. This preliminary investigation sought to investigate whether a single IMU on the shin is capable of identifying conditions of poor technique during seven lower limb exercises. Nine healthy volunteers (five male, four female, age: $26.3 \pm 6.7$ years, height: $1.77 \pm 0.08 \mathrm{~m}$, weight: $73.4 \pm 8.7 \mathrm{~kg}$ ) performed the exercises firstly with correct technique and then with different conditions of poor technique. Acceleration and angular velocity were recorded from the IMU positioned on the shin during all exercise performance conditions. Maximum and minimum acceleration and angular velocity (in $\mathrm{X}, \mathrm{Y}, \mathrm{Z}$ ) and the range of each were calculated for each condition. A paired $t$ test was used to analyse whether there was a difference in the IMU parameters between the different exercise conditions. Joint range of motion at the hip, knee and ankle were calculated using data derived from a marker based motion analysis system in order to confirm that expected deviations had occurred. The data presented has revealed that a single IMU can be used to identify the conditions of poor technique during five of the seven exercises studied. This investigation provides preliminary evidence to suggest that one IMU placed on the shin can be used to identify poor technique during seven common rehabilitation exercises, however pattern recognition techniques must be developed in order to facilitate objective real time performance measurement and feedback.
\end{abstract}

Keywords- Rehabilitation; Biofeedback; Exercise Performance

\section{INTRODUCTION}

Exercise therapy has long been prescribed to patients as part of their rehabilitation following orthopaedic surgery.

However, poor exercise technique can often result in poor outcomes for these patients and delay their return to full function. Exercise biofeedback offers a potential solution. Biofeedback has been used for more than fifty years in rehabilitation to facilitate normal movement patterns after injury [1]. It provides real-time information to patients through auditory, visual or haptic signals. Providing patients and indeed clinicians with biofeedback during exercise can have significant therapeutic effects. It can provide feedback on exercise accuracy, allowing patients to adjust their movements to the correct position during rehabilitation without the need for a clinician to be present. In addition, biofeedback may provide an incentive to exercise and therefore may be used to help overcome the problem of poor adherence to an exercise programme [2].

Virtually any physiological activity that can be measured can act as feedback during exercise. Biofeedback of balance and gait symmetry can be delivered using force platforms and optical motion capture systems can be used to deliver kinematic biofeedback. While these systems provide a high degree of accuracy they are generally restricted to a laboratory environment due to their expense and the elaborate set up required. If biofeedback applications are to be accepted into clinical practice they must prove effective both in terms of outcome and cost. In addition user friendly biofeedback systems which require minimal set up should be implemented in order to improve exercise programme adherence.

Inertial measurement units (IMUs) have been used to examine and quantify human movements. They are relatively inexpensive, easy to use and are not restricted to a laboratory environment. IMUs are also small and unobtrusive, therefore allowing unrestricted measurement of human movement. Accelerometer-based systems have been used to examine basic temporospatial gait parameters, shock attenuation, and segmental accelerations of the body during gait [3].

IMUs have also been investigated as biofeedback tools. A number of researchers have investigated the role of inertial based sensing biofeedback in balance training. Reference [4] used gyroscopes to provide biofeedback of angular trunk displacement during static and dynamic balance training in both healthy community-dwelling older adults and healthy young adults. Reference [5] also examined the effects of a gyroscopic biofeedback system on trunk sway during dual tasking (performing a cognitive and a motor task) while walking. Reference $[6,7]$ evaluated the effectiveness of using an audio biofeedback system based on accelerometric sensors for improving postural stability and balance in healthy subjects and in patients with bilateral vestibular loss.

Research has also shown that sensor based feedback from an accelerometer can be given to subjects in order to modify their movement or behaviour. Reference [8] examined the use of a biofeedback system which used a single accelerometer to 
correct neck posture in computer users. Reference [9] found that real-time visual feedback from an accelerometer could be used to achieve immediate reductions in tibial acceleration and vertical-force loading rates and thus reducing that individual's risk of a stress fracture.

Recent work has also evaluated the efficacy of IMUs as a means of assessing the quality of exercise performance. Reference [10] used five body worn accelerometers to evaluate exercise performance during lower limb exercises performed by healthy college students. This study presented a classifier (AdaBoost) that was able to distinguish correct from incorrect performance of the three exercises studied. This classifier demonstrated high specificity and sensitivity; however this system was not able to detect multiple errors at once. More recently, the same authors [11] evaluated the use of multi label classifiers to assess exercise performance in patients with knee osteoarthritis. Similar to the earlier report, five sensor nodes were used in this study, however this time each contained a tri-axial gyroscope as well as a tri-axial accelerometer. The classifiers used in this study showed high accuracy, sensitivity and specificity in detecting errors that can occur during the two lower limb exercises studied. [12] evaluated data obtained from three IMUs positioned at the hip, knee and ankle to estimate joint angles during rehabilitation exercises. This was a larger scale study than the two previously mentioned studies, including twenty young, healthy, adult participants. Joint angles were estimated from the IMU data using a kinematic model and an extended Kalman filter. The algorithm used was tested against motion capture data obtained during the exercises. This study found that the algorithm used can accurately estimate joint angles during lower limb exercises, however the quality of exercise performance was not classified.

These three studies relied on data obtained from multiple IMUs to quantify exercise performance. However, using multiple IMUs can be cumbersome and time consuming to set up. Minimising the number of IMUs required to deliver biofeedback, reduces the set up time required and thus may improve adherence. [13] assessed the feasibility of using a single accelerometer to monitor the movements of healthy elderly participants in an unsupervised home setting and found high compliance rates over a two-three month period.

Reducing the number of IMUs required is also a more cost effective option for the user.

A number of studies have looked at the use of a single IMU to classify activities [14-15]. More recently the effectiveness of providing biofeedback of lower limb exercise performance from a single IMU has been evaluated [16-18]. While the results of these reports are encouraging, it has yet to be established whether a single IMU is capable of identifying poor exercise technique during lower limb exercises, particularly during exercises involving multiple limb segments and planes of movement. This study sought to provide a preliminary perspective on this area by investigating whether a single IMU placed on the shin can identify common deviations from correct technique in seven common lower limb exercises that involve movement of three limb segments.

\section{METHODOLOGY}

This study was conducted to determine whether a single IMU can discriminate between different levels of exercise performance and identify poor exercise technique. IMU data were acquired while each participant performed seven exercises with correct technique and correct biomechanical alignment. IMU data were then acquired while the same exercises were performed with poor technique or commonly observed deviations from correct technique and biomechanical alignment. In order to confirm that the planned deviations had occurred simultaneous measurement with a marker based motion capture system was used.

\section{A. Participants}

Nine healthy volunteers (five male, four female, age: $26.3 \pm$ 6.7 years, height: $1.77 \pm 0.08 \mathrm{~m}$, weight: $73.4 \pm 8.7 \mathrm{~kg}$ ) participated in this investigation. They had no past history of neurological or musculoskeletal disease, no lower limb fractures or condition that would impair their performance during lower limb exercises. Each participant signed a consent form prior to participation in the study and the study protocol was approved by the University Human Research Ethics Committee review board.

\section{B. Exercises}

Table 1 outlines the exercises studied and details how each exercise is performed. The exercises studied were; heel slide exercise, straight leg raise exercise, inner range quadriceps exercise, knee extension in sitting exercise, hip abduction in standing exercise, hip flexion in standing exercise and hip extension in standing exercise. These exercises were adapted from the Total Hip Replacement Exercise Guide of the American Academy of Orthopaedic Surgeons [19]. While they are relatively simple exercises to perform they are frequently performed incorrectly by patients when not supervised. This study sought to investigate whether a single IMU is capable of identifying deviations in exercise technique during these seven lower limb exercises. In order to identify the deviations that commonly occur during these exercises a questionnaire was distributed among a panel of expert physiotherapists. The commonly occurring deviations that were indentified by the panel of physiotherapists are outlined in table 1. Each deviation was examined in this study.

\section{Experimental Procedures}

The participants were instructed to wear a pair of shorts and a light t-shirt during the testing procedure to allow for placement and identification of the testing apparatus. Inertial sensor data were acquired using a single IMU (SHIMMER, Shimmer research, Dublin, Ireland) secured to the participant's right shin using a Velcro strap garment with an elasticised pouch in which a sensor was placed (Fig. 1). This sensor placement was selected based on a clinical judgement 
of the sensor location that would most likely identify deviations. The orientation and location of the IMU was consistent for all study participants. The IMU is $5.3 \mathrm{~cm} \mathrm{x}$ $3.2 \mathrm{~cm} \times 1.5 \mathrm{~cm}$, weighs 15 grams and is unobtrusive, thus not hindering movement. The IMU contained both a tri-axial accelerometer and a tri-axial gyroscope sampling at $100 \mathrm{~Hz}$. Data were acquired in real time using a custom-built application for an android phone.

The Cartesian Optoelectronic Dynamic Anthropometer (CODA) motion capture system (Charnwood Dynamics, Leicestershire, UK) was also used to acquire kinematic data during the exercise. This data was used to confirm that the planned deviations had occurred. In order to calculate internal joint centres of the hip, knee and ankle joints the following anthropometric measurements were made using a calliper; pelvis width, pelvis depth, knee width and ankle width. The lengths of the thigh, shank and foot were also measured using a measuring tape. Markers were placed on each participants' right lower limb on the following anatomical landmarks: the posterior inferior lateral aspect of the heel, the lateral aspect of the fifth metatarsal head, the anterior aspect of the lateral malleolus, and the lateral aspect of the knee joint line. Wands with anterior and posterior markers attached were positioned on the pelvis and sacrum, the thigh and the tibia. The femoral wand was aligned perpendicular to the knee joint line, while the tibial wand was aligned perpendicular to the ankle joint line. The markers and wands were fixed to the skin using double sided adhesive tape. The CODA data were collected at a sampling rate of $100 \mathrm{~Hz}$.

Participants were given verbal instructions and a demonstration by a physiotherapist on how to perform each exercise with correct technique and biomechanical alignment (good). Kinematic and IMU data were collected while the participant performed the exercise five times. The first repetition was used as a practice trial and was therefore discarded from the analysis. The physiotherapist was present to determine whether the participant had performed the exercise correctly. Once each exercise had been performed with the correct technique the participant was given a short break before the exercises were repeated, this time with deviations in exercise technique. The participant was given verbal instructions and a demonstration on how to perform each exercise condition.

\section{Table 1. Exercise Studied}

\begin{tabular}{|c|c|c|}
\hline Exercise & Description of Exercise & Deviation (s) \\
\hline Heel Slide & $\begin{array}{l}\text { In supine lying, the } \\
\text { exercise is performed by } \\
\text { flexing the hip and knee to } \\
\text { slide the foot closer to the } \\
\text { ipsi-lateral hip. }\end{array}$ & $\begin{array}{l}\text {-Excessive } \\
\text { external rotation } \\
\text { at the hip during } \\
\text { the exercise (ER) }\end{array}$ \\
\hline $\begin{array}{l}\text { Straight Leg } \\
\text { Raise }\end{array}$ & $\begin{array}{l}\text { In supine lying, the } \\
\text { exercise is performed by } \\
\text { flexing the hip lifting the } \\
\text { leg off the supporting } \\
\text { surface while keeping the } \\
\text { knee in full extension. }\end{array}$ & $\begin{array}{l}\text { - Excessive knee } \\
\text { flexion (Knee } \\
\text { Flx) } \\
\text { - Excessive ankle } \\
\text { plantarflexion } \\
\text { (Pflx) }\end{array}$ \\
\hline $\begin{array}{l}\text { Inner Range } \\
\text { Quadriceps } \\
\text { Extension }\end{array}$ & $\begin{array}{l}\text { A roll/wedge is placed } \\
\text { under the knee to be } \\
\text { exercised. The exercise is } \\
\text { performed by contracting } \\
\text { the quadriceps femoris } \\
\text { muscle to bring the knee } \\
\text { from a position of slight } \\
\text { flexion into full extension. }\end{array}$ & $\begin{array}{l}\text { - Excessive ankle } \\
\text { plantarflexion } \\
\text { (Pflx) } \\
\text { - Lifting whole } \\
\text { leg off supporting } \\
\text { surface (Thigh } \\
\text { Lifts) }\end{array}$ \\
\hline $\begin{array}{l}\text { Knee } \\
\text { Extension in } \\
\text { Sitting }\end{array}$ & $\begin{array}{l}\text { In sitting, with upper thigh } \\
\text { supported on the chair, the } \\
\text { exercise is performed by } \\
\text { contracting the quadriceps } \\
\text { femoris muscle to bring } \\
\text { the knee from a position of } \\
\text { flexion into full extension. }\end{array}$ & 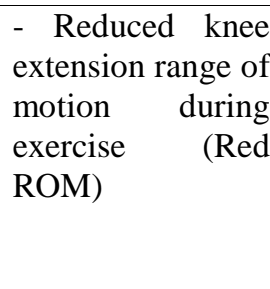 \\
\hline $\begin{array}{l}\text { Hip } \\
\text { Abduction }\end{array}$ & $\begin{array}{l}\text { In standing, the exercise is } \\
\text { performed by lifting the } \\
\text { leg out to the side. }\end{array}$ & $\begin{array}{l}\text { - Excessive lateral } \\
\text { flexion of trunk } \\
\text { (Lat Flx Trunk) } \\
\text { - Excessive hip } \\
\text { flexion (Hip Flx) }\end{array}$ \\
\hline Hip Flexion & $\begin{array}{l}\text { In standing, the exercise is } \\
\text { performed by lifting the } \\
\text { leg forwards out in front } \\
\text { of the body. }\end{array}$ & $\begin{array}{l}\text { - Excessive trunk } \\
\text { flexion (Trunk } \\
\text { Flx) }\end{array}$ \\
\hline $\begin{array}{l}\text { Hip } \\
\text { Extension }\end{array}$ & $\begin{array}{l}\text { In standing, the exercise is } \\
\text { performed by lifting the } \\
\text { leg backwards out behind } \\
\text { the body. }\end{array}$ & $\begin{array}{l}\text { - Excessive trunk } \\
\text { flexion (Trunk } \\
\text { Flx) } \\
\text { - Excessive } \\
\text { flexion knee } \\
\text { Flx) }\end{array}$ \\
\hline
\end{tabular}

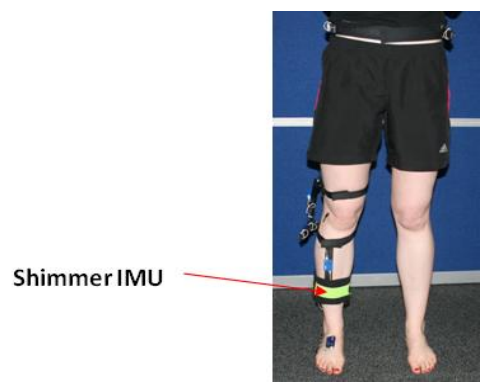

Figure 1. SHIMMER IMU placement 


\section{Data Analysis}

The following parameters were obtained from the IMU for analysis; maximum and minimum acceleration (accel) in $\mathrm{X}, \mathrm{Y}$, $\mathrm{Z}$ and maximum and minimum angular velocity (gyro) in $\mathrm{X}$, $\mathrm{Y}, \mathrm{Z}$. The range of acceleration and angular velocity was then calculated from the maximum and minimum values. The mean and standard deviation (SD) of each were calculated. Joint range of motion (ROM) at the hip (sagittal, transverse and frontal plane ROM), knee (sagittal plane ROM) and ankle (sagittal plane ROM) were obtained from the CODA motion capture system for analysis. The mean and standard deviation (SD) of each were calculated.

A paired $t$ test was used to analyse whether there was a difference in the IMU parameters between the different exercise conditions. A paired $t$ test was also used to determine whether there was a difference in the joint ROM variables obtained from the CODA motion capture system between the different exercise conditions. A $P$ value $<0.05$ was considered statistically significant. Where more than two conditions were compared, a Bonferroni adjusted significance level was used $(p=0.0167)$ to reduce the chance of type 1 error.

\section{RESULTS}

Table 2 outlines the kinematic data obtained from the CODA motion capture system. The data presented is the data used to confirm that the expected displacements had occurred during each exercise condition. While differences were observed in the joint ROM variables between the exercise conditions, significant differences were not observed between every condition. Table 3 outlines the acceleration (meters per second squared $\left(\mathrm{m} / \mathrm{s}^{2}\right)$ ) and angular velocity (radians per second ( $\mathrm{rad} / \mathrm{s})$ ) range for each exercise performed with correct exercise technique and with the deviations studied.

For the heel slide exercise, three IMU parameters (acceleration $\mathrm{x}$ and angular velocity $\mathrm{y}$ and $\mathrm{z}$ ) were able to identify when the external rotation at the hip deviation occurred ( $p<0.05)$. In figure 2 angular velocity $(y)$ during the heel slide exercise for all nine participants is shown to demonstrate the difference between correct performance of the exercise and the external rotation condition.

Two deviations were studied for the straight leg raise exercise; flexion at the knee and plantarflexion at the ankle. There was a significant difference $(\mathrm{p}<0.167)$ in acceleration ( $\mathrm{y}$ and $\mathrm{z}$ ) and angular velocity (x) between the condition of correct exercise technique and the condition where the exercise was performed with flexion occurring at the knee. For the ankle plantarflexion condition, there was a significant difference $(p=0.002)$ in acceleration $(y)$ between the condition of correct exercise technique and the ankle plantarflexion condition. There were no significant differences observed between the knee flexion and ankle plantarflexion conditions.
Table 2. Joint ROM (degrees) variables which confirm that the planned deviations occurred for each exercise condition.

\begin{tabular}{|c|c|c|c|}
\hline Exercise & \multicolumn{3}{|c|}{ Mean (SD) } \\
\hline Heel Slide & Good & ER & \\
\hline $\begin{array}{l}\text { Hip - transverse plane } \\
\text { ROM }\end{array}$ & $9.20(2.37)$ & $\begin{array}{c}29.21 \\
(10.51)^{\mathrm{a}}\end{array}$ & \\
\hline Straight Leg Raise & Good & Knee Flx & Pflx \\
\hline $\begin{array}{l}\text { Knee - sagittal plane } \\
\text { ROM }\end{array}$ & $8.12(2.44)$ & $\begin{array}{c}35.17 \\
(11.38)^{\mathrm{a}}\end{array}$ & $7.72(3.10)$ \\
\hline $\begin{array}{l}\text { Ankle - sagittal plane } \\
\text { ROM }\end{array}$ & $11.74(7.71)$ & $12.49(5.61)$ & $22.73(15.47)$ \\
\hline $\begin{array}{l}\text { Inner Range } \\
\text { Quadriceps Extension }\end{array}$ & Good & Thigh Lifts & Pflx \\
\hline $\begin{array}{l}\text { Hip - sagittal plane } \\
\text { ROM }\end{array}$ & $1.88(0.73)$ & $13.67(4.39)^{\mathrm{a}}$ & $1.74(0.97)$ \\
\hline $\begin{array}{l}\text { Ankle - sagittal plane } \\
\text { ROM }\end{array}$ & $11.78(7.49)$ & $6.03(3.90)$ & $\begin{array}{c}23.72 \\
(12.45)^{\mathrm{a}}\end{array}$ \\
\hline Knee Extension & Good & Red ROM & \\
\hline $\begin{array}{l}\text { Knee - sagittal plane } \\
\text { ROM }\end{array}$ & $67.80(7.22)$ & $49.86(6.68)^{\mathrm{a}}$ & \\
\hline Hip Abduction & Good & Hip Flx & $\begin{array}{c}\text { Trunk Lat } \\
\text { Flx }\end{array}$ \\
\hline $\begin{array}{l}\text { Hip - sagittal plane } \\
\text { ROM }\end{array}$ & $13.29(6.71)$ & $34.52(6.09)^{\mathrm{a}}$ & $13.15(4.46)$ \\
\hline $\begin{array}{l}\text { Hip - frontal plane } \\
\text { ROM }\end{array}$ & $29.29(4.52)$ & $24.01(6.87)$ & $21.48(8.35)^{\mathrm{a}}$ \\
\hline Hip Flexion & Good & Trunk Flx & \\
\hline $\begin{array}{l}\text { Hip - sagittal plane } \\
\text { ROM }\end{array}$ & $47.81(16.95)$ & $55.44(20.44)$ & \\
\hline Hip Extension & Good & Knee flx & Trunk flx \\
\hline $\begin{array}{l}\text { Hip - sagittal plane } \\
\text { ROM }\end{array}$ & $22.20(7.74)$ & $23.61(9.21)$ & $19.56(8.21)$ \\
\hline $\begin{array}{l}\text { Knee - sagittal plane } \\
\text { ROM }\end{array}$ & $16.66(3.62)$ & $59.19(8.57)^{\mathrm{a}}$ & $13.38(5.57)$ \\
\hline
\end{tabular}

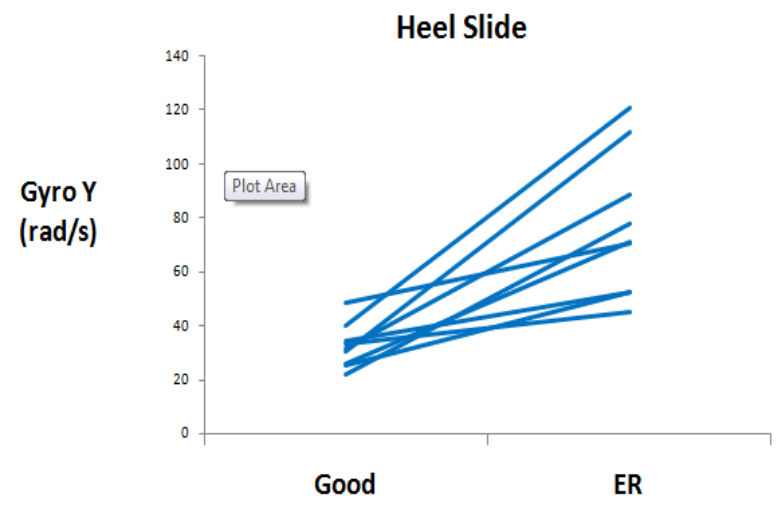

Figure 2.Angular velocity (y) for all nine participants during the heel slide exercise. Correct performance of the exercise was compared to the external rotation deviation. 
Table 3. Mean acceleration $\left(\mathrm{m} / \mathrm{s}^{2}\right)$ and angular velocity $(\mathrm{rad} / \mathrm{s})$ data for each exercise condition

\begin{tabular}{|c|c|c|c|}
\hline Exercise & \multicolumn{3}{|c|}{ Condition } \\
\hline Heel Slide & Good & ER & \\
\hline Accel X & 0.2407 & $0.7397^{\mathrm{a}}$ & \\
\hline Accel Y & 0.6477 & 0.6559 & \\
\hline Accel Z & 0.4933 & 0.5822 & \\
\hline Gyro X & 71.0182 & 83.1988 & \\
\hline Gyro Y & 32.3919 & $76.9218^{a}$ & \\
\hline Gyro Z & 27.2307 & $45.1205^{\mathrm{a}}$ & \\
\hline Straight Leg Raise & Good & Knee Flx & Pflx \\
\hline Accel X & 0.3072 & 0.2497 & 0.2638 \\
\hline Accel Y & 0.7262 & $0.3856^{\mathrm{a}}$ & $0.5616^{\mathrm{a}}$ \\
\hline Accel Z & 0.4997 & $0.2625^{\mathrm{a}}$ & 0.4131 \\
\hline Gyro X & 83.9973 & $39.8837^{\mathrm{a}}$ & 67.3483 \\
\hline Gyro Y & 27.3446 & 31.2018 & 29.3631 \\
\hline Gyro Z & 27.7818 & 17.5991 & 25.2643 \\
\hline Inner Range Quadriceps Extension & Good & Thigh Lifts & Pflx \\
\hline Accel X & 0.1568 & 0.1699 & 0.1444 \\
\hline Accel Y & 0.2352 & 0.3209 & 0.2407 \\
\hline Accel Z & 0.1507 & 0.1870 & 0.1318 \\
\hline Gyro X & 36.4416 & 40.8538 & 34.7551 \\
\hline Gyro Y & 19.4098 & 23.2484 & 20.0739 \\
\hline Gyro Z & 11.1615 & 14.1045 & 11.1601 \\
\hline Knee Extension & Good & Red ROM & \\
\hline Accel X & 0.3113 & 0.2288 & \\
\hline Accel Y & 0.5759 & $0.3526^{\mathrm{a}}$ & \\
\hline Accel Z & 0.7930 & $0.6271^{\mathrm{a}}$ & \\
\hline Gyro X & 139.1352 & 116.6247 & \\
\hline Gyro Y & 25.4645 & 22.2933 & \\
\hline Gyro Z & 52.3650 & 42.1017 & \\
\hline Hip Abduction & Good & Hip Flx & Lat trunk Flx \\
\hline Accel X & 0.5692 & 0.5559 & 0.5867 \\
\hline Accel Y & 0.2877 & $0.4196^{\mathrm{a}}$ & $0.4336^{\mathrm{a}}$ \\
\hline Accel Z & 0.2659 & 0.3969 & 0.2567 \\
\hline Gyro X & 31.0156 & $96.6646^{\mathrm{a}}$ & 35.8205 \\
\hline Gyro Y & 62.9085 & 63.3058 & 52.3379 \\
\hline Gyro Z & 86.2623 & 103.5262 & 106.2152 \\
\hline Hip Flexion & Good & Trunkflx & \\
\hline Accel X & 0.3234 & 0.3495 & \\
\hline Accel Y & 0.5407 & 0.5790 & \\
\hline Accel Z & 0.5294 & 0.5703 & \\
\hline Gyro X & 156.1519 & 168.4379 & \\
\hline Gyro Y & 36.8252 & 40.1296 & \\
\hline Gyro Z & 64.8422 & 69.1982 & \\
\hline Hip Extension & Good & Knee Flx & Trunk Flx \\
\hline Accel X & 0.1934 & $0.3272^{\mathrm{a}}$ & 0.2071 \\
\hline Accel Y & 0.2398 & $0.8255^{\mathrm{a}}$ & $0.4752^{\mathrm{a}, \mathrm{b}}$ \\
\hline Accel Z & 0.4427 & $0.7999^{\mathrm{a}}$ & $0.5692^{a, b}$ \\
\hline Gyro X & 74.0892 & $199.0711^{\mathrm{a}}$ & 104.5047 \\
\hline Gyro Y & 34.8392 & $50.2684^{\mathrm{a}}$ & 35.5183 \\
\hline Gyro Z & 20.2611 & $69.7649^{a}$ & $24.9138^{\mathrm{b}}$ \\
\hline
\end{tabular}

a = A significant difference from condition in first column

${ }^{b}=$ A significant difference from condition in second column 
For the inner range quadriceps extension exercise, two deviations were compared (thigh lifts from support and ankle plantarflexion) to the correct exercise technique condition. No significant differences $(\mathrm{p}>0.0167)$ in acceleration nor angular velocity were observed between all three conditions. The knee extension exercise was performed with correct technique and a reduced range of knee extension motion. Significant differences $(\mathrm{p}<0.05)$ in acceleration $(\mathrm{y}$ and $\mathrm{z}$ ) were observed between the two conditions.

Two deviations (hip flexion and trunk lateral flexion) were examined for the hip abduction exercise. For the hip flexion condition, significant differences were observed in acceleration y $(\mathrm{p}=0.01)$ and angular velocity $\mathrm{x}(\mathrm{p}=0.005)$ between this condition of poor technique and the correct exercise technique condition. Comparing the trunk lateral flexion deviation and the correct exercise technique condition significant differences were observed in acceleration y $(\mathrm{p}=$ 0.007). No differences were observed between the hip flexion deviation and the trunk lateral flexion deviation. The hip flexion exercise was performed with correct exercise technique and with the incorrect technique condition of trunk flexion. No significant differences were observed between these two conditions for any IMU parameter.

Correct performance of the hip extension exercise was compared to two deviations; flexion at the knee and flexion of the trunk. Comparing correct technique with the knee flexion deviation, significant differences $(\mathrm{p}<0.0167)$ were displayed in acceleration $(\mathrm{x}, \mathrm{y}, \mathrm{z})$ and angular velocity $(\mathrm{x}, \mathrm{y}$ and $\mathrm{z})$.

Comparing correct technique with the trunk flexion condition, significant differences $(\mathrm{p}<0.0167)$ were observed in acceleration y and z. Comparing the two deviations studied, significant differences were observed for acceleration $y(p=$ $0.003)$, acceleration $\mathrm{z}(\mathrm{p}=0.001)$ and angular velocity $\mathrm{z}(\mathrm{p}=$ 0.002 ). Figure 3 outlines angular velocity in $\mathrm{z}$ for the hip extension exercise. While variability is seen between participants the trend for the three exercise performance conditions is consistent for all participants.

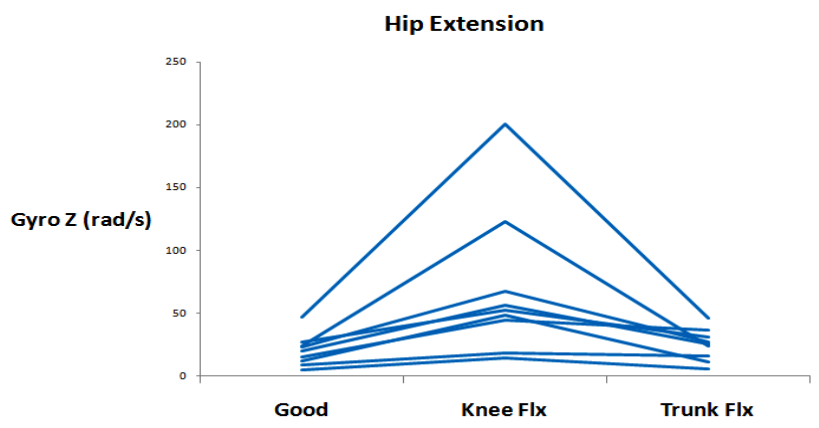

Figure 3. Angular velocity $\mathrm{z}$ for all nine participants during the hip extension exercise. Correct performance of the hip extension exercise was compared to two deviations; flexion at the knee and flexion of the trunk.

\section{DISCUSSION}

This study sought to investigate whether a single IMU placed on the shin is able to discriminate between different levels of exercise performance and identify deviations in exercise technique. The analysis performed in this study found that a single IMU can identify these deviations during five of the seven exercises studied. This study provides preliminary evidence to support the use of a single IMU as an input to a biofeedback tool.

Providing patients with biofeedback during exercise may have significant therapeutic effects. Delivering feedback on the accuracy of an exercise, will allow patients to correct their movements in real-time, without the need for a clinician to be present. In addition, providing patients with biofeedback may give them an incentive to exercise and therefore may be used to overcome the problem of poor adherence to an exercise programme. Improving exercise technique and adherence to an exercise programme may result in better outcomes for patients from rehabilitation. Biofeedback has been used for many years in rehabilitation, however, unlike traditional biofeedback methods, using an IMU to provide biofeedback is a relatively inexpensive method. Therefore, it is practical for use in the home environment.

The value of using IMUs to evaluate gross human motions such as gait and to monitor physical activity is widely recognised [20-22]. However quantifying the quality of exercise performance with inertial sensors is a relatively new area of research. Three recent studies [10-12] have described methods for assessing performance using IMU data obtained during lower limb exercises. Multiple sensors were used in these investigations, which is neither convenient nor feasible for home use. This current report is the first to our knowledge, to evaluate exercise performance using a single IMU. Using a single IMU, minimises the set up time required and therefore may be suitable for use in the home environment.

In this investigation, both acceleration and angular velocity in three planes of movement were obtained from the IMU for analysis. These features were able to identify deviations in exercise technique in five out of the seven exercises studied. However these parameters could not distinguish when trunk flexion occurred during the hip flexion exercise nor when the inner range quadriceps exercise was performed with two deviations in exercise technique (thigh lifts from support and ankle plantarflexion). Obtaining further IMU parameters, such as pitch, roll and yaw may have indentified these deviations.

The location at which the IMU is placed on the body is also an important consideration in the measurement of body movement. IMUs are normally attached to the ankle and shank to study leg movements [21]. This current investigation examined IMU data acquired from a single IMU located on the shin. Future work should examine different sensor locations on the lower limb. 
This study has a number of limitations which need to be considered. This study only examined deviations in exercise technique that were identified by a panel of expert physiotherapists. A number of other deviations may occur in reality. This study also only examined seven simple exercises that are used in rehabilitation. Future studies should examine more complex exercises such as a lunge or squat exercise.

While this work is encouraging, future work is required. The accuracy of this method of detecting deviations in exercise performance needs to be established. Pattern recognition techniques must then be developed in order to facilitate objective real-time performance measurement and feedback. Extending the identification of exercise performance, from superficial analysis to a machine learning task would therefore be the next logical step. Models such as Neural Networks, Support Vector Machines or Decision Trees could be trained, using samples of different performance conditions, to automatically classify exercise performance. Therefore, much further work is required to develop this work into an objective pattern recognition technique as relying on the superficial analysis presented in this preliminary investigation would not be justified. Nevertheless the superficial analysis performed here provides preliminary evidence to suggest that a single IMU on the shin can be used to identify a number of deviations during exercise.

\section{REFERENCES}

[1] Tate, J.J. and Milner, C.E. 2010. Real-time kinematic, temporospatial and kinetic biofeedback during gait retraining in patients; a systematic review. Physical Therapy, 90 (8), 1123-1134.

[2] Doyle, J., Kelly. J. and Caulfield, B. 2011. Design considerations in therapeutic exergaming. In Proceedings of the $5^{\text {th }}$ International Conference on Pervasive Computing Technologies for Healthcare. (Dublin, Ireland 2011).

[3] Kavanagh, J. J. and Menz, H. B. 2008. Accelerometry: a technique for quantifying movement patterns during walking. Gait Posture, 28, 1-15.

[4] Davis, J. R., Carpenter, M. G., Tschanz, R., Meyers, S., Debrunner, D., Burger, J. and Allum, J. H. J. 2010. Trunk sway reductions in young and older adults using multimodal biofeedback. Gait \& posture, 31, 465-472.

[5] Verhoeff, L. L., Horlings, C. G. C., Janssen, L. J. F., Bridenbaugh, S. A. and Allum J. H. J. 2009. Effects of biofeedback on trunk sway during dual tasking in the healthy young and elderly. Gait \& posture, 30, 76-81.

[6] Dozza, M., Chiari, L., Chan, B., Rocchi, L., Horak, F. B. and Cappello, A. 2005a. Influence of a portable audiobiofeedback device on structural properties of postural sway. Journal of NeuroEngineering and Rehabilitation, 2, 0003-2.

[7] Dozza, M., Chiari, L. and Horak, F. B. 2005b. Audiobiofeedback improves balance in patients with bilateral vestibular loss. Archives of physical medicine and rehabilitation, 86, 1401-1403.

[8] Breen, P. P., Nisar, A. and Ó'Laighin, G. 2009 Evaluation of a single accelerometer based biofeedback system for real-time correction of neck posture in computer users. In Proceedings of the 31st Annual international Conference on Engineering in Medicine and Biology, (Minneapolis, USA 2009). IEEE, 7269-7272.

[9] Crowell, H. P., Milner, C. E., Hamill, J. and Davis, I. S. 2010. Reducing impact loading during running with the use of real-time visual feedback. The Journal of orthopaedic and sports physical therapy, 40, 206.

[10] Taylor, P. E., Almeida, G. J., Kanade, T. and Hodgins, J. K. 2010. Classifying human motion quality for knee osteoarthritis using accelerometers. In Proceedings of the IEEE Engineering in Medicine and Biology Society conference. (Buenos Aires, Argentina 2010) 339-43.

[11] Taylor, P. E., Almeida, Hodgins, J. K. and G. J., Kanade, T. 2012. Multi-label classification for the analysis of human motion quality. In Proceedings of the IEEE Engineering in Medicine and Biology Society conference. (San Diego, California, USA) 2214-2218.

[12] Lin, J.F.S. and Kulić, D. 2012. Human pose recovery using wireless inertial measurement units. Physiological Measurement, 33, 2099-2115.

[13] Mathie, M.J., Coster, A.C.F., Lovell, N.H., Celler, B.G. Lord S.R. and Tiedemann, A. 2004. A Pilot study of longterm monitoring of human movements in the home using accelerometry. Journal of Telemedicine and Telecare, 10 (3) , 144-151

[14] Lee, S.H., Park, H.D., Hong, S.Y., Lee, K.J. and Kim, Y.H. 2003. A study on the activity classification using a triaxial accelerometer. In Proceedings of the IEEE Engineering in Medicine and Biology Society conference. (Cancun, Mexico) 2941-2943.

[15] Ravi, N., Dandekar, N., Mysore, P. and Littman. M.L. 2005. Activity recognition from accelerometer data. In Proceedings of the $20^{\text {th }}$ National conference on Artificial Intelligence. (Pittsburgh, Pennsylvania, USA) 1541-1546.

[16] Caulfield, B., Blood, J., Smyth, B. and D. Kelly. 2011. Rehabilitation exercise feedback on android platform. In proceedings of the $2^{\text {nd }}$ conference on Wireless Health. (San Diego,USA, 2011).

[17] Doyle, J, Kelly, D., Patterson,M., and Caulfield, B. 2011. The effects of visual feedback in therapeutic exergaming on motor task accuracy. In Proceedings of Virtual Rehabilitation (ICVR) 2011 International Conferenc. (Zurich, Switzerland, 2011).

[18] O’Huiginn, B., Coughlan, G., Fitzgerald, D., Caulfield, B. and Smyth, B. Therapeutic exergaming. In Proceedings of Wearable and Implantable Body Sensor Networks. (Berkeley, Calafornia, USA 2009).

[19] The American Academy of Orthopaedic Surgeons. 2007. Total Hip Replacement Exercise Guide. [Online]. Available: http://orthoinfo.aaos.org/topic.cfm?topic $=\mathrm{a} 00303$ [Accessed 10 June 2012]. 
[20]Aminian, K. and Najafi, B. 2004. Capturing human motion using body-fixed sensors: outdoor measurement and clinical applications. Computer animation and virtual worlds, 15:79-94.
[21] Godfrey, A., Conway, R., Meagher, D. and O. Laighin, G. 2008. Direct measurement of human movement by accelerometry. Med Eng Phys, 30:1364-86.

[22] Kavanagh, J. J. and Menz, H. B. 2008. Accelerometry: a technique for quantifying movement patterns during walking. Gait Posture, 28, 1-15. 